\section{Estudo \\ CoDebate}

em Cestão

Planejamento
Revista Estudo \& Debate, Lajeado, v. 24, n. 1, 2017. ISSN 1983-036X

DOI: http://dx.doi.org/10.22410/issn.1983-036X.v24i1a2017.1161

\title{
O OLHAR DE UM GRUPO DE ATORES SOCIAIS SOBRE O MONUMENTO NATURAL DAS ÁRVORES FOSSILIZADAS DO TOCANTINS
}

\author{
Aline Maria Costantin ${ }^{1}$, Etiene Fabbrin Pires $^{2}$, André Jasper ${ }^{3}$
}

\begin{abstract}
Resumo: O presente estudo avaliou a percepção ambiental de um grupo de doze atores sociais em relaçáo à Unidade de Conservação denominada Monumento Natural das Árvores Fossilizadas do Tocantins (MNAFTO), localizado na cidade de Filadélfia-Tocantins-Brasil. Como metodologia, utilizou-se de pesquisa qualitativa através do método survey, com a aplicação de entrevista semiestruturada, composta por questóes abertas. As respostas das perguntas foram transcritas e agrupadas em categorias elaboradas e analisadas a partir da perspectiva da análise do discurso. O resultado encontrado demonstrou que os atores sociais entrevistados perceberam mudanças na rotina da comunidade a partir da instalação do Monumento, sendo de forma positiva quando consideradas as questóes relacionadas a preservaçáo ambiental, mas também de forma negativa em razão de problemas fundiários. Também é relatada a mudança quanto à maneira de enxergar os fósseis principalmente com a obtenção de informações advindas de maneira informal. Foram sugeridas, pelos entrevistados, as atividades de Educaçáo Ambiental e Turismo, bem como foi constatada a percepçáo de que há necessidade da realizaçáo de açóes de educaçáo ambiental adicionais por parte da gerência do MNAFTO bem como a melhoria da forma de manejo atual.
\end{abstract}

Palavras-chave: Conservação. Patrimônio Ambiental. Fitofósseis. Unidades de Conservaçáo. Percepção Ambiental.

\section{THE LOOK OF A SOCIAL ACTORS GROUP ON NATURAL MONUMENT OF THE TOCANTINS FOSSIL TREES}

\begin{abstract}
The Environmental perception of a group of twelve social actors in relation to Conservation Unit named Natural Monument of the Tocantins Fossil Trees (MNAFTO), located in Filadélfia city, at Tocantins State, Brazil, was evaluated. Using the survey method, a qualitative study was conducted and semi-structured
\end{abstract}

1 Doutoranda do Programa de Pós-Graduaçáo em Ambiente e Desenvolvimento (PPGAD) do Centro Universitário UNIVATES. E-mail: aline@ifto.edu.br

2 Professora do Programa de Pós-Graduação em Biodiversidade, ecologia e conservação da Universidade Federal do Tocantins (UFT). E-mail: etienefabbrin@mail.uft.edu.br

3 Professor do Programa de Pós-Graduação em Ambiente e Desenvolvimento (PPGAD) do Centro Universitário UNIVATES. E-mail: ajasper@univates.br 
interviews with open questions were applied. The answers to the questions were transcribed and grouped into categories and analyzed from the perspective of discourse analysis. The results showed that respondents observed changes in the community routine since the monument was created. These changes were positively noted when related to conservation issues. However, they were cited as negative when related to land ownership. The way that the population deals with the fossils is also mainly related to non-formal information. Activities concerning Environmental Education and Tourism were suggested, in addition to increasing management quality of the MNAFTO.

Keyword: Conservation; Environmental Heritage. Fitofossils. Conservation Area. Environmental Perception.

\section{INTRODUÇÁO}

Os atores sociais são formadores de opiniáo e possuem a capacidade de apresentar para a população aos quais estão inseridos, ideias, valores e informaçôes sem a necessidade de maiores comentários sobre o assunto (CRUZ, 2011).

Para Souza (1991, p. 54) "o ator é alguém que representa, que encarna um papel dentro de um enredo, de uma trama de relaçóes". Sendo assim, um ator social é um indivíduo que representa algo para um grupo, uma classe, ou um país, ou ainda, o ator social pode ser uma instituição representada por um sindicato, ou partido político, jornais, rádios, etc.

Podemos ainda, vincular a figura dos atores sociais aos formadores de opinióes que são identificados nas comunidades em geral como "intelectuais, jornalistas, professores, líderes de classes, empresários, lideranças comunitárias, etc.” (BOURDIEU, 1980, p. 20).

A análise da influência dos atores sociais tem sido tema de muitos estudos que tratam da temática ambiental, seja com foco na percepção, seja com foco na gestão ambiental (CARVALHO, E.; SILVA; CARVALHO, J., 2012; FIGUEIRÊDO; SOUZA, 2013; SUESS; BEZERRA; CARVALHO SOBRINHO, 2013).

A pesquisa da percepção de atores sociais com relação a Unidades de Conservação (UC), tem sido desenvolvida no Brasil por Ferreira (2005), Bacci; Santos (2013), Besen; Bellezani (2013), Figueirêdo; Souza (2013) e Jacobi et al. (2013).

Nesse sentido, o Estado do Tocantins, no município de Filadélfia abriga uma UC muito particular, denominada Monumento Natural das Árvores Fossilizadas do Tocantins (MNAFTO). Esta UC é de Proteção Integral da categoria monumento natural, com base na legislação federal e no que pode ser detectado na legislação estadual (Estado do Tocantins) conforme sua lei de criaçáo Lei $\mathrm{n}^{\circ} 1.179$, de 04 de outubro de 2000, tendo, portanto, o objetivo de preservar sítios naturais raros (Art. 12 e seus parágrafos da Lei Federal n 9.985):

Art. 12. O Monumento Natural tem como objetivo básico preservar sítios naturais raros, singulares ou de grande beleza cênica.

$\$ 1^{\circ}$ O Monumento Natural pode ser constituído por áreas particulares, desde que seja possível compatibilizar os objetivos da unidade com a utilização da terra e dos recursos naturais do local pelos proprietários.

$\$ 2^{\circ}$ Havendo incompatibilidade entre os objetivos da área e as atividades privadas ou não havendo aquiescência do proprietário às condiçôes propostas pelo órgáo responsável pela administraçáo da unidade para a coexistência do Monumento Natural com o uso da propriedade, a área deve ser desapropriada, de acordo com o que dispóe a lei. 
$\$ 3^{\circ} \mathrm{A}$ visitação pública está sujeita às condições e restrições estabelecidas no Plano de Manejo da unidade, às normas estabelecidas pelo órgão responsável por sua administração e àquelas previstas em regulamento (BRASIL, 2000, grifo nosso).

Dessa forma, esta UC é um campo muito promissor para pesquisas de percepção ambiental, visto que a comunidade ali instalada vivencia de forma direta as consequências da instalação e manutenção de uma UC.

O principal objetivo deste artigo é a verificação da percepção ambiental de um grupo de atores sociais com relaçáo ao MNAFTO, com vistas a fornecer subsídios teóricos para a elaboração de estratégias que pretendam alcançar um modelo de gestáo participativa, além de contribuir para a mitigação, prevençáo e resolução de problemas em unidades de conservação, conforme já citado por Silva, Cândido \& Freire (2009).

\section{CAMINHOS TEÓRICOS}

A compreensão do patrimônio é um marco que expressa o vínculo de identidade da população com seu território, tornando essencial para a sua conservação a participação social (MISATO; ZANIRATO, 2013). Nesse sentido, para analisarmos um grupo de atores sociais, em relação ao MNAFTO, utilizamos os caminhos teóricos sobre o Patrimônio Natural e da Percepção Ambiental e, por último, a percepção de atores sociais em UC’s.

\subsection{Patrimônio Natural}

O conceito utilizado mundialmente sobre o Patrimônio Natural, corroborando com Ertan e Eğercioğlu (2016), Umuhire e Fang (2011), Feng et al. (2010), foi definido pela Convenção do Patrimônio Mundial realizada pela UNESCO em 1972, como:

\footnotetext{
Os monumentos naturais constituídos por formaçôes físicas e biológicas ou por grupos de tais formaçóes com valor universal excepcional do ponto de vista estético ou científico; As formaçóes geológicas e fisiográficas e as zonas estritamente delimitadas que constituem habitat de espécies animais e vegetais ameaçadas, com valor universal excepcional do ponto de vista da ciência ou da conservação;

Os locais de interesse naturais ou zonas naturais estritamente delimitadas, com valor universal excepcional do ponto de vista a ciência, conservação ou beleza natural (UNESCO, 2016, texto digital).
}

Zanirato e Ribeiro (2006) definem que o Patrimônio Natural compreende as áreas naturais que apresentam características singulares ou que registrem eventos do passado. Os autores apontam que a manutenção dessas áreas é importante por permitir o reconhecimento da história natural e por ser um laboratório para pesquisas que buscam estudar a dinâmica das reaçóes da natureza, além de geralmente apresentarem beleza cênica ou serem essenciais para o desenvolvimento de processos naturais.

Assim, é necessário salvaguardar, difundir, conservar e gerir os bens aos quais são atribuídos valor patrimonial. Para isto é importante preservar as histórias e identidades que o patrimônio expressa, além de inibir seu desaparecimento ou descaracterização através de instrumentos legais (MISATO; ZANIRATO, 2013). 
Ferretti e Comino (2015) afirmam que é importante atrelar a compreensão do patrimônio as perspectivas socioeconômicas, ecológicas, técnicas e éticas, que levam a problemas caracterizados, simultaneamente, por elevado grau de conflitos, complexidade e incerteza. A conservação do patrimônio deve incluir a participação efetiva do público a fim de gerar empoderamento de valores e processos sobre as questóes que afetam suas vidas e também influenciam na tomada de decisôes dos processos de conservaçáo (DIAN; ABDHULA, 2013).

Conforme Cairncros (2011), as pesquisas referentes ao patrimônio natural, que compreendem o patrimônio geológico ou geopatrimônio, tendem a se concentrar nos recursos geológicos de grande escala, como geoparques, geossítios, importantes afloramentos geológicos, ou na área da paleontologia, por exemplo, fósseis, traços fósseis ou sítios fósseis famosos.

Para Henriques, Tavares e Bala (2013), as atividades de geoconservação devem fortalecer a complexidade do campo, tanto em escala científica quanto em valores estéticos. A geoconservação tem que ser percebida não apenas como a conservação da geodiversidade e sim como uma preocupação social.

Avelar et al. (2015) chamam atenção a necessidade da geoconservação em nível internacional, agregando valor ao patrimônio e promovendo a participaçáo das comunidades locais para a conservação da geodiversidade.

Assim, nas atividades de geoconservação, realizadas em locais específicos, é necessária a participação das comunidades locais e do governo na elaboração e execuçáo das atividades, pois devem ser estimulados os sentimentos de pertencimento, já que muitas açôes de geoconservação estáo concentrados na escala local, sendo importante, dessa forma, levar em consideração a participação do público (MANSUR; SILVA, 2011).

\subsection{Percepçáo ambiental}

Para a conservação do patrimônio, a percepção ambiental é considerada requisito importante (CRAWFORD; BLACK, 2012). Dessa forma várias definiçōes sobre a Percepção Ambiental são apresentadas.

Tuan (1980) define a percepção ambiental como as respostas ou manifestaçóes resultantes dos processos cognitivos, tanto como os julgamentos quanto as expectativas de cada indivíduo. Para o autor, no decorrer da vida das pessoas, elas percebem, reagem e respondem continuamente de diferentes maneiras as questóes ambientais a que estão expostas, considerando os fatores que estão envolvidos na relação como educaçáo, cultura e sentimento.

Ianni (2000) apresenta a percepçáo ambiental como o significado que uma populaçáo atribui ao seu meio ambiente, em que são agregados a este significado termos como valores, identidades, interpretaçóes e conhecimentos acumulados.

Bergman (2007), Mei, Wai e Ahamad (2016) abordam que a percepção ambiental é utilizada como orientação para demonstrar atitudes e sentimentos das pessoas em relação 
ao meio ambiente. Pacheco (2009) define a percepção ambiental como as relaçóes dos indivíduos com o meio ambiente, aliadas a noção de percepção.

Para Mei, Wai e Ahamad (2016), a percepção ambiental é um gatilho que alimenta atitudes positivas e o comprometimento com o comportamento ambiental positivo. Nesta concepção a preocupação com as questôes ambientais, suas causas e impactos adversos são necessárias para medir o grau de percepção ambiental dos indivíduos, no qual quanto maior o nível cognitivo para as questóes ambientais e regimes causa efeito, maior a percepção ambiental e a tomada de atitudes positivas.

A percepção ambiental é essencial para a gestão do meio ambiente (CIRILO, 2007). Através do estudo da percepção ambiental podem ser identificadas as relações e conceitos que as pessoas (comunidades) apresentam sobre as questôes ambientais, fornecendo subsídios para a realização de trabalhos de sensibilização e sobre a importância da conservação.

Dessa forma, para atender a necessidade de estudos sobre a percepção ambiental em relação ao patrimônio natural encontrado no MNAFTO ancorou-se no conceito de Tuan (1980), devido proporcionar a análise das respostas, manifestaçóes, julgamentos e expectativas dos indivíduos em relação ao monumento.

\subsection{Atores Sociais em pesquisas de percepçáo ambiental}

A percepção ambiental pode ser observada e analisada na pesquisa social, através do olhar do pesquisador e dos atores sociais sobre o processo de conhecimento, desde sua origem até seu resultado final (MINAYO, 1999). Na pesquisa social, os atores sociais são considerados os sujeitos da pesquisa que produzem conhecimentos e práticas (CHIZOTTI, 1991). Dessa forma, em pesquisas qualitativas os pesquisadores costumam analisar os fenômenos sociais a partir da perspectiva subjetiva dos atores sociais envolvidos (SANTOS, 2013).

Estudos que abordam percepção ambiental de atores sociais considerando as UC's no Brasil são raros, e especificamente considerando-se a UC em questão, é inexistente. Em um levantamento bibliográfico sobre o tema "percepção ambiental/atores sociais/UC", foram encontrados papers, artigos e dissertaçôes aqui sumarizados, nos quais os diferentes atores sociais escolhidos para participarem das pesquisas são membros da comunidade, representantes do poder público, técnicos de órgãos públicos e privados, instituições de ensino e pesquisa, agricultores, membros de conselho gestor, cooperados, secretários municipais, representantes de Organizaçóes não governamentais - ONGs e empreendedores (FADINI et al., 2010; ROCHA Di MAIO; CAMPOS, 2011; SILVEIRA-JÚNIOR;BOTELHO, 2011; CARVALHO, E; SILVA; CARVALHO, J., 2012; FIGUEIREDO; SOUZA, 2013; SUESS BEZERRA; CARVALHO SOBRINHO, 2013; SILVA; MAIA, 2013).

Fadini et al. (2010) em sua pesquisa sobre as articulaçóes ocorridas em Vargem, São Paulo, voltadas para estimular uma maior participação de atores sociais locais nas políticas públicas, especialmente as relacionadas ao turismo, identificaram que apesar dos diversos atrativos naturais e culturais encontrados na localidade, a população não os percebe como potenciais turísticos. 
Rocha, Di Maio e Campos (2011) perceberam conflitos em relação ao uso da terra e os interesses divergentes entre os atores sociais envolvidos na implantação da Área de Proteção Ambiental de Macaé de Cima, uma UC de uso sustentável. Nesta UC os atores sociais entrevistados são pessoas ligadas as atividades turísticas e tem contribuído fortemente para as mudanças sócio-espaciais ligadas principalmente ao novo uso do solo.

Silveira Júnior e Botelho (2011) analisaram a iniciativa de turismo adotada pelos caiçaras membros da Cooperguará-ecotur, localizada no município de Graraqueçaba, Paraná e refletiram sobre as possibilidades e limites do ecoturismo de base comunitária em áreas protegidas. Para isto lançaram mão da pesquisa qualitativa, que envolveu entrevistas e observação direta aplicadas a diferentes atores sociais, nas quais identificaram que o turismo de base comunitária tem possibilitado a inclusão social, além de ter contribuído para a organização social local e para a capacitação e fomento do turismo.

Carvalho, Silva e Carvalho (2012) em seu estudo sobre a percepção ambiental dos diferentes atores sociais da comunidade de Vieirópolis, Paraíba, perceberam que a maioria dos atores sociais entrevistados possuem uma percepção ambiental confusa, fragmentada, e que não consideram, no processo de conservação, aspectos de natureza social, econômica, cultural, política etc.

Figueiredo e Souza (2013) em sua pesquisa sobre os conflitos decorrentes da criação do Parque Nacional da Serra de Itabaiana (PARNASI), analisaram os atores sociais envolvidos e os impactos de suas açóes. O estudo demonstrou conflitos na criação do Parque, cujo os principais motivos foram ocasionados pela gestão administrativa e a não participação dos atores sociais no processo de institucionalização da UC.

Suess, Bezerra e Carvalho Sobrinho (2013) ao pesquisarem a percepção ambiental dos diferentes atores sociais sobre o Lago do Abreu, em Formosa, Goiás, identificaram questóes problemáticas. Entre os problemas relatados foram encontrados o descuido e o descaso com a paisagem, e os problemas relacionados a infraestrutura, segurança e limpeza.

Silva e Maia (2013) ao analisarem as relações de cooperação entre os atores sociais, de Buíque (Pernambuco, Brasil), para a promoção da atividade turística no Parque Nacional do Catimbau, constataram que "apesar da existência de algumas interaçóes cooperativas, a maioria dos atores sociais investigados não participaram do processo". Mesmo assim, elas acreditam que o parque no futuro poderá contribuir para o desenvolvimento local e sugerem a realização de mais pesquisas na UC.

A partir da análise destas pesquisas podemos concluir que, de uma forma geral, existem problemas com relação as UCs e Comunidades, relacionados a: i) percepção das localidades como potencialmente turística; ii) conflitos em relação ao uso da terra; iii) percepção ambiental de forma ampla, que considere natureza e comunidades de forma integrada; iv) exclusão de atores sociais e comunidades na implantação da UC. Como pontos positivos, citam-se i) atores sociais como protagonistas da promoção de atividades turísticas e iv) turismo de base comunitária possibilitando a inclusão social. 


\section{CARACTERIZAÇÁO DA ÁREA DE ESTUDO}

Preocupado em proteger parte do patrimônio fossilífero encontrado na Floresta Petrificada do Tocantins Setentrional (FPTS), o governo do Estado do Tocantins, em julho do ano 2000, criou a UC denominada MNAFTO. Atualmente o monumento conta com uma sede administrativa localizada no distrito de Bielândia, município de Filadélfia, região nordeste do estado do Tocantins (FIGURAS 1 e 2). Possui uma área de $321,52 \mathrm{Km}^{2}$, correspondendo a $16,17 \%$ da área do município que possui 1.988,08 $\mathrm{Km}^{2}$ (GESTO, 2016, texto digital).

Figura 1- Mapa de localização do MNAFTO em relação ao Estado do Tocantins e ao Brasil

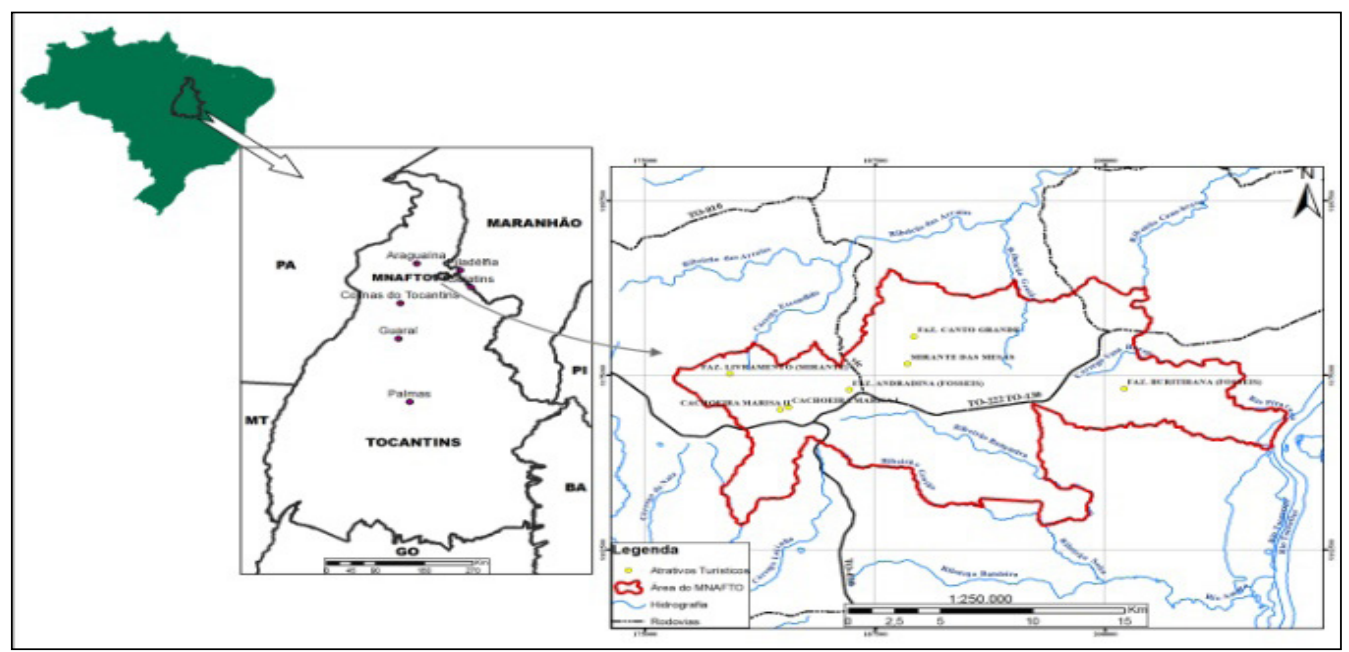

Fonte: NATURATINS (2015).

Figura 2- Imagem demonstrando a nova sede administrativa do MNAFTO, localizada no distrito de Bielândia, município de Filadélfia, Tocantins

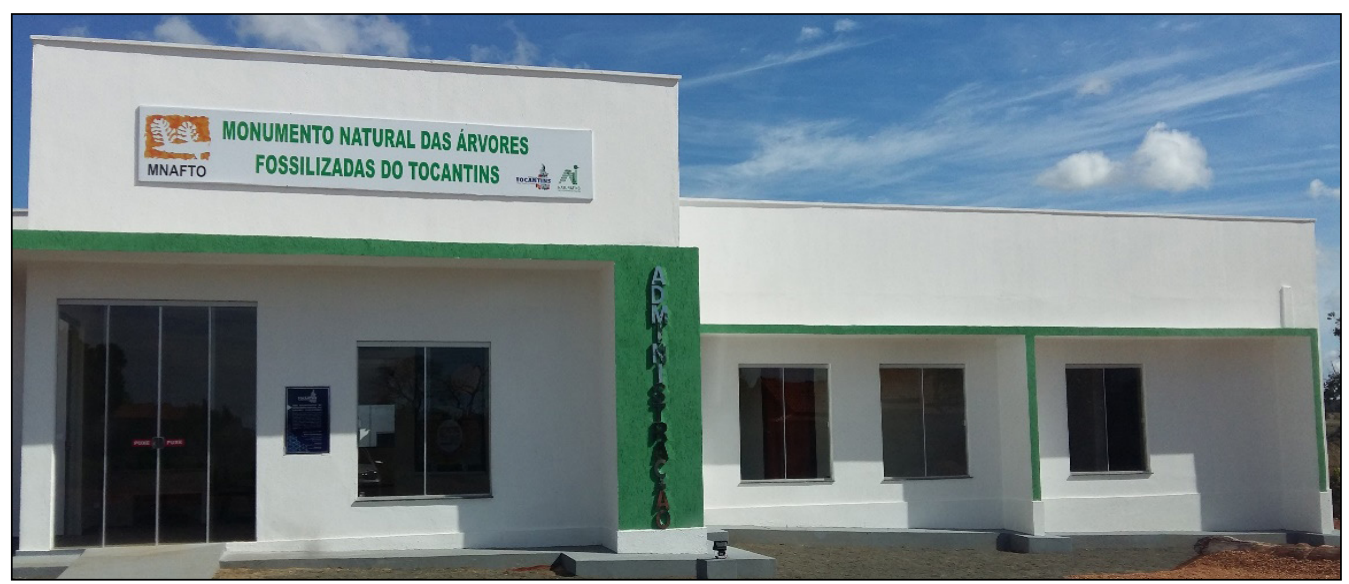

Fonte: dados da pesquisa (2015). 
O MNAFTO está localizado em uma regiáo de relevo monoclinal esculpindo os sedimentos da Bacia Sedimentar do Parnaíba, compreendendo também uma área de transição entre os relevos deprimidos da bacia do Rio Tocantins e os interflúvios da bacia do Parnaíba. Na região as altitudes mais elevadas variam entre 150 e 500 metros, "conformando uma ampla superfície inclinada para o norte, sendo drenada por afluentes do Rio Tocantins" (ARRUDA, 2005).

A área do MNAFTO é cortada pelas rodovias estaduais TO-010 e TO-222, significando um elevado fluxo de veículos circulando em seus limites, causando todos os impactos ambientais inerentes a presença de rodovias como atropelamentos de fauna, fragmentação de ambientes, distúrbios antrópicos etc. (MRS/OIKOS, 2005).

A escolha da área para a criação do MNAFTO ocorreu em um notável fragmento da FPTS, no qual os fósseis são encontrados em afloramentos distribuídos em manchas descontinuas pela área (FIGURA 3). Estes fósseis estão associados a arenitos e lamitos da Formação Mutuca quando in situ (MRS/OIKOS, 2005). A FPTS constitui um dos mais importantes registros fossilífero da flora permiana do Hemisfério Sul, cujo os portes, a qualidade e a quantidade do material encontrado impressionam (DERNBACH, 1996; DIAS-BRITO et al., 2007; KAUFFMANN, 2013b). Este rico patrimônio paleontológico tem sido tema de diversos estudos paleobotânicos dentre eles os trabalhos de Dernbach (1996), Rößler; Noll (2002), Rößler; Galtier (2002, 2003), Rößler (2006), Dias-Brito et al. (2007), Tavares (2012), Kauffmann et al. (2012), Kauffmann et al. (2013a), Kauffmann et al. (2013b), Kurzawe et al. (2013a), Kurzawe et al. (2013b), Kauffmann (2014), Benicio et al. (2014), Benicio et al. (2015), Benicio (2015), Benicio et al. (2016) e Kauffmann et al. (2016).

Figura 3- Vista geral da forma como ocorrem os fósseis na área do MNAFTO. As setas indicam fragmentos de lenhos de fósseis

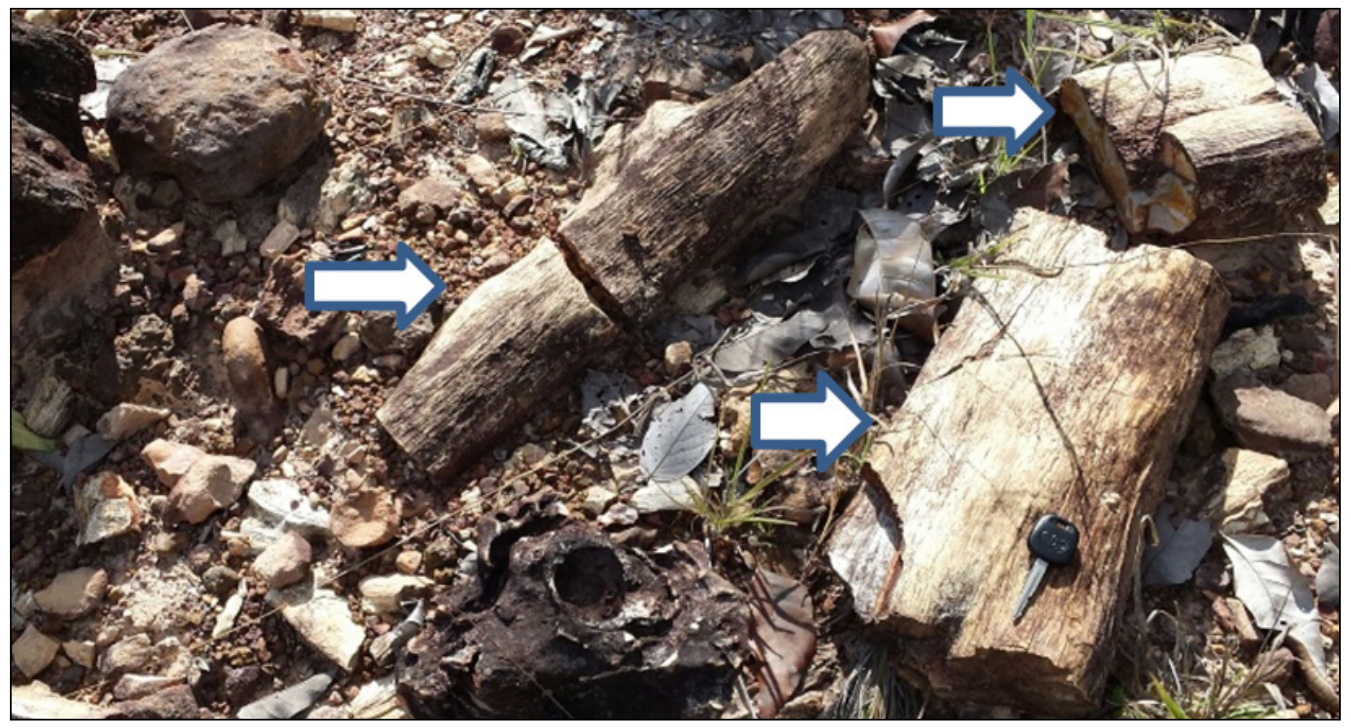

Fonte: dados da pesquisa (2015). 
OMNAFTO por ser uma UC da categoria monumento natural, permite a manutenção de propriedades particulares dentro de sua área demarcada, conforme previsão em lei para quando existe compatibilidade entre os objetivos de conservação e uso dos recursos naturais pela população (BRASIL, 2000). Assim, no MNAFTO existem propriedades particulares caracterizadas por fazendas e também por um aglomerado urbano conhecido como a sede do distrito de Bielândia (FIGURA 4). A populaçáo ali existente se estabeleceu antes da criação do MNAFTO e vem sofrendo impactos diretos e indiretos advindos da implantaçáo do monumento. A sede administrativa do monumento localiza-se no distrito de Bielândia.

A gestão do MNAFTO é realizada pelo Instituto Natureza do Tocantins (NATURATINS), órgáo estadual responsável pela execução de políticas públicas voltadas para conservação dos recursos naturais e gestão de UCs, além da implantação e execução do Plano de Manejo (GESTO, 2016, texto digital).

Figura 4- Foto panorâmica do aglomerado urbano conhecido como Bielândia (distrito), município de Filadélfia, Tocantins

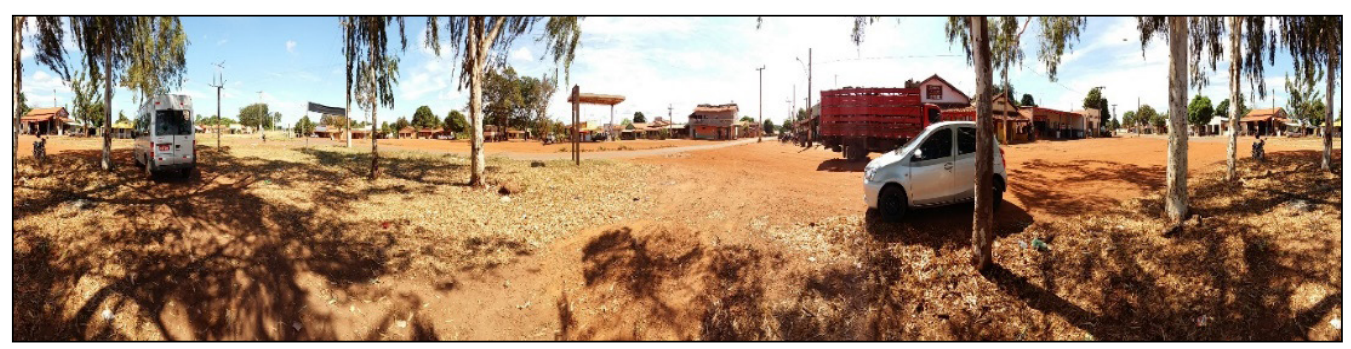

Fonte: Foto da autora (2015).

\section{METODOLOGIA E SUJEITOS DO ESTUDO}

No sentido de compreender a percepção ambiental dos atores sociais em relação ao MNAFTO foi utilizada a pesquisa de levantamento ou survey. Na pesquisa foram aplicadas entrevistas semiestruturadas com perguntas abertas a fim de se obter uma análise qualitativa.

Para a aplicaçáo das entrevistas foi utilizada conforme Barbetta (2012) a amostragem por julgamento, que permite que "os elementos escolhidos são aqueles julgados como típicos da população que se deseja estudar". Assim, foram escolhidos doze atores sociais que exercem alguma forma de influência sobre a população, sendo eles moradores do povoado de Bielândia e do município de Filadélfia. Para a aplicação das entrevistas foram utilizados: gravador de voz digital e câmera fotográfica digital modelo celular Samsung Galaxy A5, além de anotaçôes em caderneta de campo.

Para compor este artigo foram utilizadas questôes abertas de entrevistas semiestruturada, sendo elas: 1) Qual atividade você exerce? 2) Mudou de alguma forma a rotina do povoado-cidade com a criação do MNAFTO? a) Como? 3) A criação do MNAFTO mudou à sua maneira de enxergar os fósseis? a) Como ocorreu esta mudança? 4) Quais atividades você acha que devem ser realizadas no MNAFTO? 5) Qual sua opiniấo 
sobre o manejo dos fósseis encontrados na região? e 6) Qual sua sugestão para a revisão do Plano de Manejo do MNAFTO?

Para a análise das entrevistas foram atribuídos códigos sequenciais de identificação variando de S1 a S12 aos entrevistados, a fim de não permitir a identificação dos atores sociais envolvidos na pesquisa e contribuir com a sistematização das respostas através do software estatístico SPSS 22.

As respostas das perguntas foram transcritas na íntegra e agrupadas em categorias elaboradas a partir da identificação de similaridades das respostas durante a leitura de cada questão. A sistematização seguiu procedimentos descritos por Moraes (1999), que reforça o processo de categorização como uma metodologia de pesquisa para descrever e interpretar o conteúdo dos dados coletados. Através do agrupamento das respostas foi possível a sistematização dos dados em tabelas.

As respostas transcritas foram editadas e analisadas a partir da perspectiva da análise do discurso. Segundo Orlandi (2005, p.15), a palavra discurso "etimologicamente, tem em si a ideia de curso, de percurso, de correr por, de movimento”. Não foram realizadas ediçóes nas respostas e a escolha das falas utilizadas ocorreu de maneira subjetiva devido alguns atores sociais terem dados respostas muito curtas e diretas aos questionamentos.

Com vistas a atender ao que estabelece a Resolução 466/2012 do CONEP/Brasil em relação à análise de discurso, os instrumentos aqui apresentados foram submetidos ao Conselho de Ética e Pesquisa - COEP/UNIVATES tendo sido devidamente analisados e aprovados (Processo CAAE:39337614.1.0000.5310, Parecer 914.733).

\section{RESULTADOS E DISCUSSÓES}

Os atores sociais realizam diversas atividades na comunidade, sendo que foram selecionados para as entrevistas dois gestores do MNAFTO, um líder religioso, dois gestores públicos, dois diretores de escolas (municipal e estadual), três moradores da região do MNAFTO (sendo dois residentes no povoado do distrito de Bielândia e um na zona rural do distrito de Bielândia) e dois moradores da sede do município de Filadélfia, sendo estes um rural e outro urbano (TABELA 1), 3 são do sexo feminino e 9 do sexo masculino com idade mínima de 25 e a máxima de 72 anos.

Tabela 1- Distribuição dos atores sociais de Bielândia envolvidos no estudo de acordo com a atividade exercida

\begin{tabular}{lc}
\hline Atividade & Quantidade de atores sociais \\
\hline Funcionário Público & 5 \\
Professor (a) & 4 \\
Aposentado & 2 \\
Comerciante & 1 \\
\hline
\end{tabular}

Fonte: dados da pesquisa (2015). 
A maioria dos entrevistados desenvolvem funções públicas, considerando que os professores são funcionários públicos das redes municipal e estadual de ensino. Assim, dentre as atividades desenvolvidas pelos entrevistados, consideramos que as funçôes púbicas possuem atributos de agentes reguladores e os professores geralmente são formadores de opiniōes. Essas diferenças nas atividades também contribuem com a possibilidade de diferentes percepçóes em relação ao mesmo assunto. Dessa maneira, conforme Bourdieu (1980), os atores podem causar influência na população de Filadélfia (CRUZ, 2011).

Na segunda questáo, os entrevistados foram indagados a respeito de percepçáo sobre mudanças na rotina do povoado de Bielândia e na sede do município de Filadélfia a partir da instalação do Monumento (TABELA 2).

Tabela 2- Quantificação das respostas relacionadas à percepção da mudança da rotina do povoado de Bielândia devido a criação do MNAFTO

\begin{tabular}{lc}
\hline Como mudou a rotina do povoado-cidade & Quantidade de atores sociais \\
\hline Não responderam & 2 \\
Mudança negativa & 3 \\
Mudança positiva & 7 \\
\hline
\end{tabular}

Fonte: dados da pesquisa (2015).

Mais da metade dos entrevistados (TABELA 2) perceberam que ocorreram mudanças na rotina do povoado de Bielândia ou na sede do município de Filadélfia com a criação e implantaçáo do MNAFTO. Esta mudança, pôde ser categorizada como positiva ou negativa. Como exemplo de percepçóes positivas citam-se as seguintes falas:

Por exemplo, ela passou a ser mais bem vista a cidade, por causa desse monumento que era uma coisa esquecida antes (ATOR SOCIAL, S5).

A partir do MNAFTO as pessoas começaram a entender a sua valorizaçáo e a partir daí o uso dos recursos naturais passou a ser visto de forma diferente. Porque muitos usavam antes do MNAFTO os recursos naturais de qualquer forma, hoje já tem um cuidado e procuram se informar para utilizar de forma correta (ATOR SOCIAL, S2).

Noutra perspectiva, três atores sociais responderam que ocorreram mudanças negativas na rotina do povoado-cidade, e os motivos podem ser evidenciados nas seguintes falas:

Preocupação fundiária. Até que ponto eu possuo o que é meu. A questão financeira mesmo (ATOR SOCIAL, S3).

Ficou receoso sobre a desapropriação, com medo (ATOR SOCIAL, S7).

Mudou para pior, ninguém consegue negociar terra, mediram para titular e não deram os títulos (ATOR SOCIAL, S10). 
Sumarizando-se, na análise desta questão, percebe-se que o MNAFTO mudou a rotina da comunidade, e as opinióes divergem quanto o efeito desta mudança. A atribuição de um valor negativo, neste caso é evidenciada pela preocupaçáo fundiária, visto que se evidencia uma preocupação a respeito da posse das terras situadas geograficamente na área (ou entorno) da UC. Já as argumentaçóes enquadradas como mudanças positivas, relatam modificações com relação à preservação dos recursos naturais, que teria sido melhorada.

Quando levamos em consideração a UC como questáo positiva na comunidade, podemos ponderar que muitos dos atores entrevistados possuem nível de escolaridade elevado (8 entrevistados com nível superior). Em Filadélfia somente 5,4\% dos habitantes com 25 anos ou mais de idade possui nível superior completo (ATLAS BRASIL, 2016, texto digital). Dessa forma, a amostragem aqui analisada não reflete proporcionalmente a realidade do município, visto que o compromisso deste artigo é com atores sociais e náo de representaçấo estatística da comunidade.

Neste sentido, em pesquisas com percepção ambiental $\mathrm{X}$ escolaridade, temos resultados que demonstram que há uma correlação positiva entre educação e conhecimento sobre o meio ambiente (SUDARMADI et al., 2001; TORGLER; GARCÍA-VALIÑAS, 2007; NASIBULINA, 2015). Dessa forma, a percepção positiva dos entrevistados pode ser reflexo do nível de escolaridade dos entrevistados, pois entre os atores sociais entrevistados oito possuem nível superior, três possuem nível médio e apenas 1 nível fundamental de escolaridade (dados da pesquisa, 2015).

Também pode-se considerar a questáo levantada por Silva, Cândido e Freire (2009), que relatam que em regiôes carentes, a populaçấo local pode perceber a UC como um meio de aproximação ao poder público e, assim, imaginar uma possível melhoria de suas condiçóes sociais, ou ainda, como relatam os autores, esta percepção pode ser fruto de uma associação à ideia de segurança a seus moradores. Em Filadélfia o Îndice de Desenvolvimento Humano (IDH) é 0,621, considerado médio conforme o Programa das Nações Unidas para o Desenvolvimento (IBGE, 2016, texto digital).

Por outro lado, quando analisamos as respostas que consideram a UC de forma negativa, podemos avaliar a questáo da criaçáo da UC ou a sua gerência, e ainda a questão fundiária levantada pelos entrevistados.

Silva et al. (2005) avaliam que em muitos casos, as UC são criadas sem considerar os moradores da região, causando conflitos sociais diversos. Este tipo de situação acaba por gerar percepçóes negativas, devido a diversos fatores, como por exemplo a limitaçáo no uso do espaço. No caso do MNAFTO, conforme consta em seu plano de manejo, a UC foi criada com o intuito de combater a exploração ilegal dos fósseis e protegê-los, através da Medida Provisória ${ }^{\circ}$ de 11 de setembro de 2000, logo em seguida regulamentada pela Lei 1.179 de 04 de outubro de 2000 (MRS/OIKOS, 2005).

Esses conflitos causados pela regularização fundiária e uma possível desapropriação de seus imóveis também foram encontrados por Shiraishi (2010), em sua pesquisa sobre Percepção Ambiental na reserva Biológica da Contagem, Distrito Federal, na qual as pessoas que se manifestaram de forma negativa estavam preocupadas com a finalidade e repercussão 
da pesquisa por temerem a remoção de seus imóveis devido a regularização fundiária da reserva.

Ainda, de acordo com Silva et al. (2005), não existem boas relaçóes entre as populaçóes de áreas protegidas e as instituiçóes gerenciadoras no Brasil. Para o autor, o que falta é diálogo entre as partes.

Considerando-se tanto a visão da UC como positiva quanto negativa, há de se considerar que a percepção é algo individual, e dessa forma, de acordo com Tavares et al. (2013), cada pessoa atribui um significado aquilo que percebe, conforme suas experiências cotidianas e intrínsecas, em que o processo mental de interação do indivíduo com o ambiente é refletido no processo da percepção ambiental.

Para Bergman (2007), as pessoas possuem além do conhecimento sobre o ambiente atitudes sobre ele. Dentre as formas de se expressar as pessoas manifestam suas preferências, gostos ou desgostos por lugares. Frequentemente ocorrem atitudes conflitantes em relaçáo ao ambiente, no qual essas pessoas têm sentimentos negativos, positivos ou ambivalentes em relação às mesmas características ambientais, corroborando assim com a necessidade da realização de estudos sobre a percepção ambiental de comunidades em áreas de proteção ambiental para a gestão de UCs e seu entorno.

Quando questionados sobre a ocorrência de mudanças na maneira de enxergar os fósseis após a criação do MNAFTO, nove atores sociais perceberam a ocorrência dessa mudança (TABELA 3).

Tabela 3- Caracterização da mudança na maneira de enxergar os fósseis pelos entrevistados após a criação do MANFTO

\begin{tabular}{lc}
\hline Motivo da mudança de visão dos fósseis & Quantidade de atores sociais \\
\hline Não responderam & 2 \\
Não mudou & 1 \\
Mudou & 9 \\
\hline
\end{tabular}

Fonte: dados da pesquisa (2015).

Esta mudança é evidenciada nos discursos:

A gente não dava valor. Hoje em dia se dá valor. Sabe que é muito importante (ATOR SOCIAL, S5).

Primeiro não dava importância aos fósseis. É informação cultural (ATOR SOCIAL, S6).

Percebe-se que na análise das respostas, a mudança na "maneira de enxergar os fósseis" se deu principalmente de acordo com a obtenção de informaçóes advindas de maneira informal, conforme evidencia-se na fala do ator social S7: 
Quando iniciou o monumento, a gente sabia da existência dos fósseis, mas não sabia o que ele era (sic). Sabia que era a árvore que virou pedra (sic). Daí depois vieram os estudos e o NATURATINS, vieram um monte de pesquisa (sic) e os estudantes (ATOR SOCIAL, S7).

De acordo com Clary e Wandersee (2014), os adultos aprendem, primeiramente, a ciência em ambientes de aprendizagem informal. No caso do MNAFTO, a maneira de enxergar os fósseis mudou através da aquisição de conhecimento dos atores sociais em sua maioria fora da sala de aula, em ambientes informais, através de contato com pesquisadores que estiveram na localidade em investigaçôes de campo e de intervenções de educação ambiental, realizadas pelo NATURATINS e parceiros.

Outra questão a ser levada em consideração, é a modificação da forma popular de entender os fósseis da localidade. Historicamente, a população local denomina os fósseis como "pedras de pau" (GESTO, 2016 texto digital). Na fala do ator social S2, observa-se que ocorreu uma mudança e/ou entendimento nessa denominaçáo:

Antes do MNAFTO não se tinha conhecimento desse material, chamava-se de pedra de pau, a partir do MNAFTO e com a busca do conhecimento hoje e sabe um pouco da real história do aparecimento desses fósseis (ATOR SOCIAL, S2).

Nesse sentido, Bresolin, Zakrzevski e Marinho (2010), perceberam que os sujeitos (atores sociais) envolvidos com o processo de criação de UCs e com as ações realizadas nas mesmas, agregaram aos conceitos ecológicos os aspectos sociais, culturais e práticos, no qual os sujeitos passaram a perceber o ambiente de uma forma mais sistêmica, onde se estabeleceram diferentes níveis de complexidade, uso, conservação e identidade.

Torres e Oliveira (2008) também perceberam em sua a análise de percepção ambiental em uma UC, a contribuição da população para o aperfeiçoamento do projeto favorecendo a adoção de comportamentos conservacionistas que consequentemente contribuem para uma conservação mais efetiva.

Para Paula, Silva e Gorayeb (2014), os critérios norteadores das intervençóes educativas junto as populaçóes locais e entornos de UC devem levar em conta o entendimento atual da percepção ambiental e o conhecimento da dinâmica geoecológica da paisagem a fim de contribuir com o planejamento e a gestão ambiental.

$\mathrm{Na}$ fala do ator social S9, percebe-se que há uma preocupação quanto ao apoio governamental:

Quando passei a conhecer a função do monumento, percebi que ele é importante e deveria ter mais apoio da populaçáo e do governo (ATOR SOCIAL, S9).

Em relação ao apoio governamental para as UCs no estado do Tocantins, este é realizado através de açôes previstas no Plano Plurianual (PPA), no caso o que está em vigor é para o período 2016 -2019, e tem previsto em um de seus objetivos, a proteção da biodiversidade com a gestão de UC e reabilitação da fauna (SEPLAN, 2016, texto digital). 
Ao serem questionados sobre sugestôes de atividades para serem realizadas no MNAFTO, os atores sociais em sua maioria sugeriram açóes de Educaçáo Ambiental e Turismo (TABELA 4).

Tabela 4- Atividades sugeridas pelos entrevistados a serem desenvolvidas no MNAFTO

\begin{tabular}{lc}
\hline Atividades que devem ser desenvolvidas no MNAFTO & Quantidade de atores sociais \\
\hline Educação Ambiental & 4 \\
Pesquisa & 1 \\
Turismo & 5 \\
Não soube sugerir & 2 \\
\hline
\end{tabular}

Fonte: dados da pesquisa (2015).

Observa-se que a soma das atividades Educaçáo Ambiental e Turismo alcançou a maioria das atividades sugeridas pelos atores sociais para serem realizadas no MNAFTO (TABELA 4). Estas atividades são corroboradas na fala:

Turismo e Educação ambiental, essas duas são essências (ATOR SOCIAL, S4).

Os resultados aqui encontrados quanto a esta questáo corroboram com os resultados encontrados por Bresolin, Zakrzevski e Marinho (2010), que em um estudo sobre percepçáo ambiental de atores sociais, relataram que os entrevistados, ao serem questionados sobre os problemas que afetam a UC analisada, apontaram principalmente falta de diálogo, comunicação e envolvimento da comunidade com o Parque. Dessa maneira, sugeriram, assim como no estudo em questão, medidas de Educação Ambiental que estimulem a construção de conhecimentos, sobre a UC, junto à população. Bem como, sugeriram atividades de pesquisa, de lazer/turismo e atividades de comunicação ambiental.

A consulta sobre açóes a serem realizadas aos moradores das comunidades instaladas em UCs é de grande valia, pois segundo Fontana (2004), Silva, Cândido e Freire (2009) estudos de percepção podem apontar soluçóes para problemas ambientais. Shiraishi (2010) sugere que as comunidades diretamente afetadas por uma UC, devido à experiência de vida no local, podem identificar lacunas ou indicar mecanismos para a proteçáo ambiental.

Rodrigues et al. (2012) explicam que a educação ambiental é um instrumento importante de gestão ambiental por prover conhecimentos para a comunidade local sobre as questôes ambientais. A percepçáo da populaçáo local sobre o meio ambiente pode ser utilizada como uma ferramenta para referenciar as fragilidades e ganhos apresentados por programas de educação ambiental implantados bem como permitir o acompanhamento e ajustes necessários dos mesmos.

Nesse sentido, cita-se o trabalho de Fontana (2004), que investigou a percepção de moradores da Estação Biológica de Santa Lúcia (Espírito Santo), que segundo o autor, demonstraram conhecimento sobre a área e sobre as ameaças que atingem a UC, sendo que ainda propuseram açôes para o manejo da UC. 
Pane e Patriana (2016) referem-se à necessidade da inclusão da educação ambiental para melhorar a percepção em relação às questôes ambientais. Neste trabalho é abordada a importância de aumentar a percepçáo ambiental para a prevenção de comportamentos nocivos ao meio ambiente e a prevençáo de desastres naturais, além de melhorar a qualidade de vida da sociedade como um todo.

Zakharova, Liga e Sergeev (2015) definem que o núcleo da educação ambiental em qualquer nível é definido de forma muito clara e possui o objetivo de desenvolver comportamentos conscientes que minimizam as influências negativas e as atividades humanas nocivas ao meio ambiente, sendo que as interaçóes entre a sociedade e a natureza são fatores cruciais da gênese cultural e ecológica.

As atividades de educação ambiental podem ser desenvolvidas de várias formas e em diversos ambientes. Entre estas formas e ambientes o geoturismo pode contribuir para a realização de atividades educacionais principalmente em UCs, visto que as atividades realizadas tornam a visitaçáo uma experiência significativa de aprendizagem (PEREIRA, 2010).

Ressalta-se que conforme Hoeffel et al. (2008), o turismo deve ser organizado através de planejamento participativo e a educaçáo ambiental, envolvendo moradores e turistas, pois o turismo pode beneficiar a economia local, porém nem sempre desenvolve relaçóes harmônicas entre o homem e o meio natural.

O geoturismo é definido por Moura-fé (2015) como um segmento promissor da atividade turística. Conforme Azevedo (2007), o geoturismo é considerado uma atividade turística que tem como principal atrativo o patrimônio geológico e a busca de sua proteção por meio da conservaçáo dos recursos naturais, promovendo a divulgação e o desenvolvimento das ciências da terra através da sensibilização do turista pela interpretação do patrimônio acessível ao público leigo.

Dowling e Newsome (2010) definem o geoturismo como uma forma de turismo natural que incide especificamente sobre a geologia e a paisagem, promovendo o turismo em geossítios e a conservação da geodiversidade além de uma compreensão das ciências da terra através da valorização e da aprendizagem.

Para Cocean e Cocean (2016), o desenvolvimento do geoturismo em um território é importante em relação ao papel que desempenha no desenvolvimento do turismo responsável, com efeito positivo sobre a economia local e também para a conservação e proteção das paisagens.

O geoturismo também pode contribuir para a realização de atividades educacionais principalmente em UCs, visto que as atividades realizadas tornam a visitação uma experiência significativa de aprendizagem (PEREIRA, 2010). Ainda para Lascuraín (2001), as atividades geoturísticas dinamizam a economia nas áreas do entorno das UCs, bem como incentivam a conservaçáo das áreas por iniciativa própria das comunidades locais.

De acordo com Piranha et al. (2011), o Brasil tem um grande potencial para a criação de geoparques e o desenvolvimento do geoturismo, devido a sua diversidade natural e da necessidade da preservação de sítios geológicos 
Kauffmann (2014) em sua pesquisa sobre o MNAFTO entendeu que a área da UC e seu entorno enquadram-se nos propósitos definidos da geoconservação, propondo assim a criação de um geoparque na área.

Os atores sociais, em sua maioria, ao serem questionados sobre o manejo dos fósseis encontrados no MNAFTO perceberam a necessidade da realização de mais ações e a melhoria na forma de manejo atual (TABELA 5).

Tabela 5- Percepção dos entrevistados acerca do manejo do MNAFTO

\begin{tabular}{lc}
\hline Percepçáo sobre o manejo dos fósseis encontrados na região & Quantidade de atores sociais \\
\hline Manejo inadequadas/falta de açóes & 6 \\
Manejo adequado & 4 \\
Não responderam ou não tem conhecimento & 2 \\
\hline
\end{tabular}

Fonte: dados da pesquisa (2015).

A conservação dos fósseis encontrados no MNAFTO foi percebida pelos atores sociais que demonstraram seus pensamentos sobre a forma de manejo (TABELA 5). De acordo com Zorrila-Pujana e Rossi (2016), para realizar qualquer ação de conservação ambiental é necessário o envolvimento direto dos diferentes atores sociais. Assim, as percepçóes dos atores sociais envolvidos nesta pesquisa demonstraram que há a necessidade de melhorar o manejo dos fósseis, e há a necessidade de realizar mais ações, como o discurso do ator social S6:

Procurar melhorar a possibilidade de maior preservação. Principalmente aumentar a expansão de conservação porque estáo concentrados em vários lugares (ATOR SOCIAL S6).

A fala do ator social S6 corrobora com Silva, Cândido e Freire (2009), quando se refere a Percepção Ambiental das populações em relação as UCs, na qual as comunidades que interagem com estas áreas de proteção entendem que as áreas são úteis, mas nem sempre possuem o tamanho necessário, ou não são adequadamente geridas, isto é, nem sempre ocorre o manejo adequado para a conservação.

Corroborando ainda com a utilidade da UC, o ator social S5 discorreu:

Os produtores rurais, os fazendeiros já têm mais consciência. E até as escolas também já fizeram excursão pra levar os alunos pra ver a maneira de conservar (ATOR SOCIAL, S5).

Mattos, Nobre e Aloufa (2011) destacaram a importância positiva percebida pela comunidade que pesquisaram, através de ações de educação ambiental e maior visibilidade para a região com a implantação da UC, como no caso ocorrido no MNAFTO.

Os atores sociais, aos serem questionados quanto a apresentação de sugestôes para a revisão do Plano de Manejo do MNAFTO, em sua maioria não souberam opinar (TABELA 6). 
Tabela 6- Sugestóes dos entrevistados para a revisão do Plano de Manejo do MNAFTO

\begin{tabular}{lc}
\hline Sugestóes para revisão do Plano de Manejo do MNAFTO & Quantidade de atores sociais \\
\hline Revisar o uso público & 2 \\
Ser mais específico para as necessidades do MNAFTO & 2 \\
Prever mais ações de Educação Ambiental & 1 \\
Não apresentou sugestóes & 7 \\
\hline
\end{tabular}

Fonte: dados da pesquisa (2015).

Apesar dos atores sociais entrevistados falarem que faltam açóes ou que o plano de manejo deve ser revisto, o que se pode observar é que não há conhecimento sobre o plano. Este desconhecimento pode ter sido gerado devido ao fato de o documento náo despertar o interesse da população, pois apresenta aprofundado conteúdo técnico, conforme definição:

Documento técnico mediante o qual, com fundamento nos objetivos gerais de uma unidade de conservação, se estabelece o seu zoneamento e as normas que devem presidir o uso da área e o manejo dos recursos naturais, inclusive a implantação das estruturas físicas necessárias à gestão da unidade (Brasil, 2000).

O Plano de Manejo, independentemente de ser um documento técnico deve não somente ser um documento dos funcionários da UC, mas também um instrumento de trabalho para a comunidade e área do entorno (VIEIRA, 2007). Na construção de um Plano de Manejo a comunidade deve participar e debater através de seus conhecimentos empíricos e científicos, as oportunidades, potencialidades e os limites de uso da UC em conjunto com a equipe técnica, a fim de perceber a sua contribuição na elaboração do produto final. No caso do Plano de Manejo do MNAFTO a participação da comunidade ocorreu através de sugestóes para o zoneamento interno e para a delimitação da Zona de Amortecimento (MRS/OIKOS, 2005).

Quanto à implantação de estruturas físicas para o MNAFTO, conforme a definição do Plano de Manejo, no momento desta pesquisa estavam em fase de acabamento. Atualmente a estrutura física do MNAFTO é composta pela sede administrativa do monumento (FIGURA 2), alojamento (para pesquisadores e visitante) e garagem, que foram disponibilizadas oficialmente a sociedade em junho de 2015, logo após a realizaçáo desta pesquisa de campo. Espera-se que elas possam contribuir para o aumento do conhecimento do Plano de Manejo, pois conforme Antunes, Tôrres e Scalco (2012), a presença de estruturas físicas relacionadas à UCs implicam em consequências positivas, pois podem possibilitar um maior controle e segurança ao monumento, além de proporcionar melhores condiçóes para atender os visitantes da área.

\section{CONSIDERAÇÓES FINAIS}

A partir da análise das questôes abordadas neste artigo, podemos concluir que:

a) Os atores sociais entrevistados, em sua maioria, desenvolvem funções públicas, entre elas as funções com atributos de agentes reguladores e professores, contribuindo assim com a possibilidade de causar influências diversas sobre a população; 
b) Foi constatada a percepção de mudanças na rotina do povoado de Bielândia e na sede do município de Filadélfia a partir da instalação do Monumento. Os entrevistados perceberam que as mudanças foram positivas, atribuindo o valor positivo a questóes de preservação ambiental. Contudo, também é atribuído valor negativo a instalação da UC em razão de problemas fundiários.

c) Há a percepção de mudança quanto a maneira de enxergar os fósseis após a criação do MNAFTO. Essa mudança aconteceu principalmente com a obtenção de informaçóes advindas de maneira informal.

d) Foram sugeridas as atividades de Educação Ambiental e Turismo para serem realizadas no MNAFTO.

e) Os atores sociais perceberam que há necessidade da realização de açóes adicionais por parte da gestão do monumento, bem como melhoria da forma de manejo atual. Entre as açóes citadas pelos atores sociais se encontram a expansão da área do monumento e açóes que incentivem a conservação dos fósseis, como as ações de Educação Ambiental.

f) Apesar da maioria dos atores sociais não apresentarem sugestóes para a revisão do Plano de Manejo do MNAFTO, uma minoria sugeriu que fosse revisto o programa de uso público do monumento.

Concluindo, a Percepção Ambiental dos atores sociais entrevistados converge com o atual plano de manejo do MNAFTO. Entretanto, essas percepçóes e sugestóes apresentadas podem contribuir na reformulação do referido plano, pois foram sugeridas mais açóes de Educação Ambiental e mudanças no programa de uso público do monumento que normatiza a forma de acesso à UC. Além disso, a percepção ambiental dos atores sociais entrevistados pode influenciar a população quanto à conservação do monumento.

\section{REFERÊNCIAS}

ANTUNES, R. C.; TÔRRES, A. J. F.; SCALCO, R.F. Análise da proposta do Plano de Manejo para estruturação do Parque Estadual do Biribiri. Revista Brasileira de Ecoturismo, São Paulo, v.5, n.2, p.245-262, 2012.

ATLAS DO DESENVOLVIMENTO HUMANO DO BRASIL- ATLAS BRASIL. Perfil de sua localidade: Filadélfia -TO. Disponível em:<http://www.atlasbrasil.org.br/2013/pt/ perfil_m/filadelfia_to $>$. Acesso em: 29 set. 2016.

ARRUDA, M. B. Representatividade ecológica com base na biogeografia de biomas, ecótonos e ecorregióes continentais do Brasil - o caso do Cerrado. Doutorado, UNB; IBAMA, Brasília. 194 p. 2005.

AVELAR, S. et al. Community Perceptions for Geoconservation of a Coastal Area in Rio de Janeiro, Brazil. Geoheritage, 7, p. 275-283, 2015.

AZEVEDO, U. R. Patrimônio geológico e geoconservação no Quadrilátero Ferrífero, Minas Gerais: potencial para a criação de um geoparque da UNESCO. Tese (Doutorado) 
Programa de Pós-graduação em Geologia, Universidade Federal de Minas Gerais, Belo Horizonte, 2007.

BACCI, D. L. C; SANTOS, V. M. N. Mapeamento socioambiental como contribuição para a gestão dos recursos naturais. In: JACOBI, P. R. (Org.). Aprendizagem Social e Unidades de Conservaçáo: Aprender juntos para cuidar dos recursos naturais. São Paulo: IEE/PROCAM, 2013.

BARBETTA, P. A. Estatística aplicada às ciências sociais. 8. ed. Florianópolis: Editora da UFSC, 2012.

BENÍCIO, J. R. W. et al. Inferências paleoclimáticas baseadas em análises de crescimento lenhoso de gimnospermas da Floresta Petrificada do Tocantins Setentrional, Permiano, Bacia do Parnaíba: resultados preliminares. In: PALEO/RS 2014 - Reunião Anual Regional da Sociedade Brasileira de Paleontologia, 2014, Candelária, RS. Resumos da PALEO/RS 2014. Porto Alegre: Sociedade Brasileira de Paleontologia, v. 1. p. 8-9, 2014.

BENÍCIO, J. R. W. et al. Palaeoclimatic inferences based on dendrological patterns of permineralized wood from the Permian of the Northern Tocantins Petrified Forest, Parnaíba Basin, Brazil. Palaeobiodiversity and Palaeoenvironments, v. 96, p. 255-264, 2015.

BENÍCIO, J. R. W.; Inferências Paleoclimáticas baseadas em análises de Crescimento Lenhoso de Gimnospermas da Floresta Petrificada do Tocantins Setentrional, Permiano da Bacia do Parnaíba. Dissertação (Mestrado) - Programa de Pós-graduação em Ambiente e Desenvolvimento. Centro Universitário UNIVATES, Lajeado, 2015.

BENICIO, J. R. W. et al. Palaeoclimatic inferences based on dendrological patterns of permineralized wood from the Permian of the Northern Tocantins Petrified Forest, Parnaíba Basin, Brazil. Palaeobiodiversity and Palaeoenvironments: international journal of palaeontology and stratigraphy, v. 96, p. 255-264, 2016.

BergmanN, M. Análise da Percepção Ambiental da População Ribeirinha do Rio Santo Cristo e de estudantes e professores de duas escolas públicas, município de Giruá, RS. Dissertação (Mestrado) - Programa de Pós-graduação em Ecologia, Instituto de Biociências, Universidade Federal do Rio Grande do Sul, Porto Alegre, 2007.

BESEN, G. R.; BELLEZANI, M. L. Negociação e mediação de conflitos em Áreas de Proteção Ambiental - APAs. In: JACOBI, P. R. (Org.). Aprendizagem Social e Unidades de Conservaçáo: Aprender juntos para cuidar dos recursos naturais. São Paulo: IEE/ PROCAM, 2013.

BOURDIEU, P. A opinião pública não existe. In: THIOLLENTE, M. Crítica metodológica, investigaçáo social e enquete operária. São Paulo: Polis, 1980. 
BRASIL, Sistema Nacional de Unidades de Conservação da Natureza - SNUC: Lei $\mathbf{n}^{\circ}$ 9.985, de 18 de julho de 2000; Decreto no 4.340 de 22 de agosto de 2002. 2.ed. Brasília, DF, 2000.

BRESOLIN, A. J ZAKRZEVSKI, S. B. B. MARINHO, J. R. Percepção, Comunicação e Educação Ambiental em Unidades de Conservação: um estudo no Parque Estadual de Espigão Alto - Barracão/RS - Brasil. Perspectiva, Erechim. v. 34, n.128, p. 103-114, 2010.

CAIRNCROS, B. The National Heritage Cresource Act (1999): Can legislation protect Sout Africa’s rare geoheritage resources? ResourcePolicy, n. 36, p. 204-213, 2011.

CARVALHO, E. K. M. A; SILVA, M. M. P; CARVALHO, J. R. M; Percepçáo Ambiental dos diferentes Atores Sociais de Vieirópolis, PB. Qualit@s Revista Eletrônica, v.13, n 01, 2012.

CHIZOTTI, A. Pesquisa em Ciências Humanas e Sociais. São Paulo: Cortez, 1991.

CIRILO, C.L.B.A Comunidade do Cabocó e a Percepçáo Ambiental das Crianças e Adolescentes para a Gestáo do Rio Capibaribe. Dissertação (Mestrado) -Programa de Pós-graduação em Gestão e Políticas Ambientais, Universidade Federal de Pernambuco, Recife, 2007.

CLARY, R. M \& WANDERSEE, J.H. Lessons from US Fossil Parks for Effective Informal Science Education. Geoheritage, v.6, p. 241-256, 2014.

COCEAN, G.; COCEAN, P. An Assessment of Gorges for Purposes of Identifying Geomorphosites of Geotourism Value in the Apuseni Mountains (Romania).

Geoheritage, 2016.

CRAWFORD, K. R.; BLACK, R. Visitor Understanding of the Geodiversity and the Geoconservation Value of the Giant's Causeway World Heritage Site, Northern Ireland. Geoheritage, v.4, p. 115-126, 2012.

CRUZ, M.; A mídia e os formadores de opiniấo no processo democrático. Ponto-evírgula, n. 9, p. 35-51, 2011.

DERNBACH, U. Petrified Forest: the world's 31 most beautiful petrified forests. D’oroVerlag: Heppenheirm, 1996.

DIAN, A. M.; ABDULLAH, N.C.; Public Participation in Heritage Sites Conservation in Malaysia: Issues and challenges. Procedia - Social and Behavioral Sciences, $101 \mathrm{p}$. 248-255, 2013.

DIAS-BRITO, D. et al. Floresta Petrificada do Tocantins Setentrional: o mais exuberante e importante registro fossilífero tropical-subtropical permiano do Hemisfério Sul. In: 
Schobbenhaus, C; Campos, D. A.; Queiroz, E.T.; Winge, M.; Sítios Geológicos e Paleobiológicos (SIGEP), v. II, p.337-354, 2007.

DOWLING R. K; NEWSOME D. Global geotourism perspectives. Oxford, Goodfellow Publishers, 2010.

ERTAN, T., EĞGRCIOĞLU, Y.; The Impact of UNESCO World Heritage List on Historic Urban City Centers and Its Place in Urban Regeneration: The Case of

Melaka, Malaysia and Tire, Turkey. Procedia - Social and Behavioral Sciences, 216, p. 591- 602, 2016.

FADINI, A. A. B. et al. Políticas públicas e participação social: perspectivas de turismo sustentável em Vargem (SP). Revista Brasileira de Ecoturismo, São Paulo, v.3, n.1, p.91$108,2010$.

FENG, Di et al. Estimation on Aesthetic Value of Tourist Landscapes in a Natural Heritage Site: Kanas National Nature Reserve, Xinjiang, China. Chin. Geogra. Sci., 20, v. 1 p. 59-65, 2010.

FERREIRA, C. P. Percepção ambiental na Estação Ecológica de Juréia-Itatins. Dissertação (Mestrado) - Programa de Pós-Graduação em Ciência Ambiental, Universidade de São Paulo, São Paulo, 2005.

FERRETTI, V.; COMINO, E.; An integrated framework to assess complex cultural and natural heritage systems with Multi-Attribute Value Theory. Journal of Cultural Heritage, v.16 p. 688-697, 2015.

FIGUEIREDO, C. T., SOUZA, A. V. M. Conflitos socioambientais em áreas protegidas: o Parque Nacional da Serra de Itabaiana, em Sergipe. Cadernos de Ciências Sociais Aplicadas, Vitória da Conquista - BA, n. 14 (especial), p. 141-163, 2013.

FONTANA, A. Ao redor da natureza: investigando a percepção ambiental dos moradores do entorno da Estaçáo Biológica de Santa Lúcia, Santa Teresa ES. Dissertação (Mestrado) - Programa de Pós-Graduação em Psicossociologia de Comunidades e Ecologia Social, Instituto de Psicologia, Universidade Federal do Rio de Janeiro, 2004.

HENRIQUES, M. H.; TAVARES, A. O; BALA, A. L. M. The geological heritage of Tundavala (Angola): An integrated approach to its characterisation. Journal of African Earth Sciences, n.88, p. 62-71, 2013.

HOEFFEL, J. L. et al. Trajetórias do Jaguary - Unidades de conservação, percepção ambiental e turismo: um estudo na APA do Sistema Cantareira. Ambiente e Sociedade, São Paulo, n.11, v.1, p. 131-148, 2008. 
IANNI, A. M. Z. A produção social do ambiente na periferia da metrópole: $o$ caso da capela do Socorro. In: JACOBI, P. R. Ciência Ambiental: os desafios da interdisciplinaridade, São Paulo: Annablume - Fapesp, 2000.

INSTITUTO BRASILEIRO DE GEOGRAFIA E ESTATÍSTICA-IBGE -Censo 2010. Disponível em:< http://www.ibge.gov.br/cidadesat/topwindow.htm?1 >. Acesso em: 21 set. 2016.

INSTITUTO NATUREZA DO TOCANTINS- NATURATINS. Mapa de Localizaçáo do Monumento Natural das Árvores Fossilizadas. Palmas, TO, 2015.

JACOBI, P. R.; et al. Perspectivas futuras na Gestão Compartilhada das APAs no estado de São Paulo. In: JACOBI, P.R. (Org.). Aprendizagem Social e Unidades de Conservaçáo: Aprender juntos para cuidar dos recursos naturais. Sáo Paulo: IEE/ PROCAM, 2013.

KAUFFMANN, M. et al. Registros de ocorrências de fitofósseis na Formação Pedra de Fogo, Bacia do Parnaíba, consideraçóes preliminares quanto a tafonomia e anatomia. IN: XV SIMPOSIO ARGENTINO DE PALEOBOTÁNICA Y PALINOLOGÍA, 2012, Corrientes. Anais: XV Simposio Argentino de Paleobotánica y Palinología, 2012.

KAUFFMANN, M. et al. Gestão de Patrimônio Paleontológico, Situação e Ferramentas de conservação: o caso do Monumento Natural das Árvores Fossilizadas do Tocantins. Estudo \& Debate, Lajeado, v.20, n.2, 115-125, 2013 a.

KAUFFMANN, M. et al. Resultados preliminares do resgate de fitofósseis no Monumento natural das árvores fossilizadas do Tocantins, Bacia do Parnaíba, Tocantins, Brasil. Geonomos, v.21, n.2, 46-52, 2013 b.

KAUFFMANN, M. Mapeamento Geológico e Levantamento Paleontológico do Monumento Natural das Árvores Fossilizadas, Bacia do Parnaíba, Estado do Tocantins. Tese (Doutorado). Programa de Pós-Graduação Instituto de GeociênciasUNICAMP, Campinas, 2014.

KAUFFMANN, M. et al. Evidence for palaeo-wildfire in the Late Permian palaeotropics - charcoal from the Motuca Formation in the Parnaíba Basin, Brazil. Palaeogeography, Palaeoclimatology, Palaeoecology, v. 449, p. 455-465, 2016.

KURZAWE, F. et al. New gymnospermous woods from the Permian of the Parnaíba Basin, Northeastern Brazil, Part I: Ductoabietoxylon, Scleroabietoxylon and Parnaiboxylon. Review of Palaeobotany and Palynology, v. 195, p. 37-49, 2013 a.

KURZAWE, F. et al. New gymnospermous woods from the Permian of the Parnaíba Basin, Northeastern Brazil, Part II: Damudoxylon, Kaokoxylon and Taeniopitys. Review of Palaeobotany and Palynology, v. 195, p. 50-64, $2013 \mathrm{~b}$. 
LASCURAÍN, C.H. O ecoturismo como um fenômeno mundial. In: LINDENBERG, K.; HAWKINS, E.D. Ecoturismo: um guia para planejamento e gestão, São Paulo: SENAC, 2001.

MANSUR, K.L.; SILVA, A.S. Society's Response: Assessment of the Performance of the "Caminhos Geológicos" ("Geological Paths") Project, State of Rio de Janeiro, Brazil.

Geoheritage, v. 3, p. 27-39, 2011.

MATTOS, P.P; NOBRE, I. N; ALOUFA, M. A. I. Reserva de Desenvolvimento Sustentável: Avanço na Concepção de Áreas Protegidas? Soc. nat., Uberlândia, ano 23 n. 3, 409-422, 2011.Disponível em:<http://www.scielo.br/pdf/sn/v23n3/v23n3a04.pdf>. Acesso em 04 ago. 2016.

MEI, N.S.; WAI, C.W.; AHAMAD, R.; Environmental Awareness and Behaviour Index for Malaysia. Procedia - Social and Behavioral Sciences, 222, p. 668-675, 2016.

MINAYO, M. C. de S. O desafio do conhecimento: pesquisa qualitativa em saúde. 6.ed. São Paulo: Hucitec, 1999.

MISATO, M.T.; ZANIRATO, S.H. O Patrimônio como fator de identidade territorial e de desenvolvimento local. In: JACOBI, P.R. (Org.). Aprendizagem Social e Unidades de Conservaçáo: Aprender juntos para cuidar dos recursos naturais. São Paulo: IEE/ PROCAM, 2013.

MORAES, R. Análise de conteúdo. Educação, Porto Alegre, v.22, n.37, p.7-32, 1999.

MOURA-FE, M. M. Geoturismo: uma proposta de turismo sustentável e conservacionista para a Regiấo Nordeste do Brasil. Soc. nat., Uberlândia, v. 27, n.1, p. 53-66, 2015.

MRS/OIKOS. Plano de Manejo do Monumento Natural das Árvores Fossilizadas do Tocantins. Planos de manejo e de uso público no Monumento Natural das Árvores Fossilizadas do Tocantins e diagnóstico biofísico e sócio-econômico. 2005. Brasília: MRS, 2005.

NASIBULINA, A. Education for Sustainable Development and Environmental Ethics. Procedia - Social and Behavioral Sciences, v. 214, p. 1077-1082, 2015.

ORLANDI, E.P. Análise de Discurso: princípios e procedimentos. 6. ed. Campinas, SP, Pontes, 2005.

PACHECO, E. Percepçáo Ambiental como Desvelamento do Ethos Embrionário.

Tese (Doutorado) - Programa de Pós-Graduação em Psicossociologia de Comunidades e Ecologia Social, Universidade Federal do Rio de Janeiro, Rio de Janeiro, 2009. 
PANE, M.M; PATRIANA, R. The Significance of Environmental Contents in Character Education for Quality of Life. Procedia-Social and Behavioral Sciences, v.222, p. 244252, 2016.

PAULA, E. M. S. D.; SILVA, E. V. da; GORAYEB, A. Percepção ambiental e dinâmica geoecológica: premissas para o planejamento e gestão ambiental. Soc. nat., Uberlândia, v. 26, n. 3, p. 511-518, dez. 2014.

PEREIRA, E.S. Geodiversidade do Parque Estadual da Pedra Branca-Rj: Subsídios para o Planejamento Geoturístico. Dissertação (Mestrado) Programa de Pós-graduação em Geologia, Instituto de Geociências, da Universidade Federal do Rio de Janeiro, Rio de Janeiro, 2010.

PIRANHA, J. M. et al. Geoparks in Brazil-strategy of Geoconservation and Development. Geoheritage, v. 3, p. 289-298, 2011.

RÖßLER, R.; GALTIER, J. Dernbachiabrasiliensis gen. nov. et sp. nov. - a new small tree fern from the Permian of NE Brazil. Review of Paleobotany and Palynology, Filadelfia, v.122, p.239-263, 2002.

RÖßLER, R.; NOLL, R. Der permischeversteinerte Wald von Araguaina/Brasilien - Geologie, Taphonomie und Fossulführung.Veröffentlichungendes Museum für Naturkun de Chemnitz, v.25, p.5-44, 2002.

RÖ $\beta L E R$, R.; GALTIER, J. The first evidence of the fern Botryopteris from the Permian of the Southern Hemisphere reflecting growth form diversity. Review of Paleobotany and Palynology, Filadelfia, v.127, p.99-124, 2003.

RÖßLER, R. Tworemarkable Permian Petrified Forests: correlation, comparison and significance. In: Lucas, S.G.; Cassinis, G. ; Schneider, J.W. (Eds.). Non-Marine Permian Biostratigraphy and Biochronology. Geological Society, Special Publications, London, v. 265, v. 39-63, 2006.

ROCHA, A.P.; DI MAIO, A.C.; CAMPOS, L.G. Percepção ambiental na Área de Proteção Ambiental de Macaé de Cima: perspectivas para o ecoturismo. Anais do VIII Congresso Nacional de Ecoturismo e do IV Encontro Interdisciplinar de Ecoturismo em Unidades de Conservação. Revista Brasileira de Ecoturismo, São Paulo, v.4, n.4, p. 581, 2011.

RODRIGUES, M. L.; et al. A Percepção Ambiental Como Instrumento de Apoio na Gestão e na Formulação de Políticas Públicas Ambientais. Saúde Soc., São Paulo, v.21, supl.3, p.96-110, 2012.

SANTOS, A. R. Contribuiçóes Epistemológicas do Pensamento Complexo para a

Compreensão da Pesquisa Social, Textos \& Debates, Boa Vista, n. 20, p. 81-99, 2013. 
SECRETARIA DE PLANEJAMENTO E ORÇAMENTO -SEPLAN. Plano Plurianual 2016-2019. Disponível em:<https://central3.to.gov.br/arquivo/291433/>. Acesso em: 05out.16.

SHIRAISHI, J.C. Percepção Ambiental sobre a Reserva Biológica da Contagem, DF uma Análise Preliminar. V Encontro Nacional da Anppas, Florianópolis, 2010.

SILVA, H. P. et al. Biodiversity Conservation and Human Well-being: Challenges for the Populations and Protected Areas of the Brazilian Atlantic Forest. Eco Health, v.2, p.333342, 2005.

SILVA, J.H.; MAIA, F.B.A. Turismo, cooperação e desenvolvimento local em Unidades de Conservação: o caso do Parque Nacional do Catimbau, Buíque - PE. PASOS, v. 11, n. 4, p. 559-570, 2013.

SILVA, T. S.; CÂNDIDO, G. A.; FREIRE, E. M. X. Conceitos, percepções e estratégias para conservação de uma Estação Ecológica da caatinga nordestina por populaçóes do seu entorno. Sociedade e natureza, n. 21, v. 2, p. 23-37, 2009.

SILVEIRA-JÚNIOR, W.J.; BOTELHO, E.S. Turismo em áreas protegidas e inclusão social de populaçóes tradicionais: um estudo de caso da Cooperativa de Ecoturismo de Guaraqueçaba (PR). Revista Brasileira de Ecoturismo, São Paulo, v.4, n.3, pp.441-462, 2011.

SISTEMA DE GESTÃO DE UNIDADES DE CONSERVAÇÃO-GESTO.

Monumento Natural das Árvores Fossilizadas. Disponível em:<www.gesto.to.gov.br/ uc/44/>. Acesso em 01 out. 216.

SOUZA, H. J. Como se faz análise de conjuntura. 11a ed. Petrópolis: Vozes, 1991.

SUDAMARDI, S. et al. A survey of perception, knowledge, awareness, and attitude in regard to environmental problems in a sample of two different social groups in Jakarta, Indonesia. Environment, Development and Sustainability, n. 3, p.169-183, 2001.

SUESS, R.C.; BEZERRA, R.G., CARVALHO SOBRINHO, H. Percepção Ambiental de Diferentes Atores Sociais sobre o Lago do Abreu em Formosa-GO. Holos, Ano 29, v.6, p.241-261, 2013.

TAVARES, G.G.; et al. Lugar e percepção ambiental: estudo da vivência ambiental da comunidade das escolas municipais Ayrton Senna e Moacyr Romeu Costa, Anápolis/GO. Tecnologias da Informação em Educação.2० CONGRESSO LUSO-BRASILEIRO EM INVESTIGAÇÃO QUALITATIVA. Aveiro- Portugal, 2013. Indagation Didactica, vol. 5, n.2, outubro 2013. 
TAVARES, T. M. V. Estudo de Marattiales da "Floresta Petrificada do Tocantins Setentrional” (Permiano, Bacia do Parnaíba). Tese (Doutorado). Programa de PósGraduação em Geociências e Meio Ambiente, Instituto de Geociências e Ciências Exatas, Universidade Estadual Paulista, Rio Claro,2012.

TOCANTINS (Estado). Lei n ${ }^{\circ} 1.179$, de 04 de outubro de 2000.

TOCANTINS (Estado). Medida Provisória nº de 11 de setembro de 2000.

TORGLER, B.; GARCÍA-VALIÑAS, M.A. The determinants of individuals' attitudes towards preventing environmental damage. Ecological Economics, n. 63, p. 536-552, 2007.

TORRES, D. F; OLIVEIRA E. S. Percepção Ambiental: Instrumento para Educação Ambiental em Unidades de Conservação. Rev. Eletrônica Mestr. Educ. Ambiental 21, 2008. Disponível em:<https://www.seer.furg.br/remea/article/view/3046/1725>. Acesso em: 02 out. 2016.

TUAN, Y.F. Topofilia-Um Estudo da Percepçáo, Atitudes e Valores do Meio

Ambiente, Tradução Lívia de Oliveira, Rio Claro: UNESP, 1980.

UMUHIRE, M.L., FANG, H. Impact Assessment and Protection of Outstanding Landscape Integrity in a Natural Heritage Site: Fairy Valley, Kanas Nature Reserve, Xinjiang, China. J. Mt. Sci., n.8, p. 46-52, 2011.

UNESCO. Convençáo para a Proteção. Disponível em:<http://whc.unesco.org/archive/ convention-pt.pdf>. Acesso em 20 set. 2016.

VIEIRA, L.F.S A leitura da paisagem como instrumento para o plano de manejo: Reserva Biológica Estadual Mata Paludosa. Dissertação (Mestrado) - Programa de Pósgraduação em Geografia, Porto Alegre, RS, 2007.

ZAKHAROVA, E.; LIGA, M.;SERGEEV, D. Constructing Philosophy of Environmental Education in Contemporary Russia. Procedia - Social and Behavioral Sciences, v.214, p. 1181-1185, 2015.

ZANIRATO, S. H.; RIBEIRO, W. Patrimônio cultural: a percepção da natureza como um bem não renovável. Revista Brasileira de História. São Paulo, n.51, v. 26, p. 251$262,2006$.

ZORRILA-PUJANA, J.; ROSSI, S. Environmental education indicators system for protected areas management. Ecological Indicators, v.67, p. 146-155, 2016. 